\title{
Principals on L-plates: rear view mirror reflections
}

\section{Authors}

Helen Wildy, Murdoch University

Simon Clarke, The University of Western Australia

\section{Contact}

Associate Professor Helen Wildy

School of Education

Murdoch University

South St, Murdoch, Western Australia 6150

Phone +618 93607476

Fax +61893606280

Email H.Wildy@murdoch.edu.au

An earlier version of this paper was presented at the 2008 annual meeting of the American Educational Research Association, New York. 


\title{
Principals on L-plates: rear view mirror reflections
}

\author{
Helen Wildy \\ Murdoch University \\ Simon Clarke \\ Graduate School of Education, The University of Western Australia
}

\begin{abstract}
Purpose - This paper aims to contribute to the literature on beginning the principalship by identifying and illustrating key challenges that novice principals encounter in their first year for which they would benefit from improved preparation.
\end{abstract}

Design/methodology/approach - The paper is a synthesis of a decade of research focusing on the principal with the general aim of analysing ways in which principals can work more effectively within the realities of schools as highly complex organizations. Throughout this work, the narrative account has been used as the main approach for depicting principals' understandings of the contexts in which they find themselves and their interpretations of the experiences that confront them in their roles.

Findings - A range of findings generated from the research as a whole has been refined into the conceptualisation of four distinct but interrelated challenges facing novice principals in exercising their roles.

Originality/value - The paper proposes a conceptual framework that can be used as a heuristic tool for informing the preparation of principals, especially in the Australian context.

Keywords Principals, Preparation, Small Schools, Complexity, Narratives

Paper Type Research Paper

\section{Introduction}

Our research into the leadership of small schools in Australia seeks to fill a gap in the literature about school leadership (Dunning, 1993; Nolan, 1998; Webb and Vulliamy, 1995; Wilson, 2007). This gap is surprising. Given the key function of principals of small schools in the daily operation of their schools when compared with their peers in larger schools it might be expected that the role of the principal of the small school is a focus of research. Knowing that principals of small schools are also pivotal public people in their communities, afforded high visibility but needing high credibility, would also suggest that the role be a focus of study (Clarke, 2002a; Mohr, 2000; Nolan, 1998). This paucity of research resulted in few robust examples of effective leadership applicable for informing best practice in small school settings (Clarke, 2003). Moreover, the contextual differences between these settings and the contexts of larger schools generate their own distinctive challenges that are worthy of investigation (Southworth, 1999).

In Australia, leaders of small schools are beginning their careers. Small schools are so classified if their enrolments are below 100 students. It is assumed that in small 
schools beginners will learn the craft of leading a school, in preparation for positions in larger schools. However, two factors challenge this assumption: principals of small schools have a substantial teaching role in addition to their principal responsibilities; and they are required to attend to the same management protocols as their peers in larger schools but without the assistance of deputy principals (Dunning, 1993).

There are other well-documented reasons for studying the novice principal (Sackney and Walker, 2006). First, principals have a high impact on student achievement (Rutter et al., 1979) and so their preparation should not be left to chance. Second, school contexts are changing dramatically with implications for the complexity of principals' work, particularly in relation to the demands of accountability. Thirdly, and relatedly, the principal's work is increasingly fraught with tensions and dilemmas requiring sophisticated interpersonal skills (Wildy and Louden, 2000). Fourth, the settings in which novice principals frequently find themselves generate their own demands such as high levels of visibility, and geographical and professional isolation. Despite these demands, principals in Australian jurisdictions take up positions without any formal or specific preparation, with the expectation that they will learn on-thejob. Furthermore, such a journey to the principalship, although depicted in the literature (Su et al., 2003) as an 'apprenticeship model' with associated on-the-job theoretical and practical learning, is frequently characterised by variety, novelty and serendipity (Wildy and Clarke, 2008), and is without a firm grounding in leadership theory, practice or reflection. Indeed, understandings of principal leadership within our educational community tend to be shaped by folk wisdom and a handy set of tricks of the trade, which are ingrained into principals' approaches to their work without being brought under critical control (Eraut, 1994). Furthermore, understandings of leadership in our context continue to be confused with narrow, technicist models of management, which are not sufficient for connecting principals with the experiences and challenges of contemporary school leadership.

Given that numbers of applicants for the principalship are declining in Australia as elsewhere (d'Arbon, 2002; Preston, 2005), and the most difficult posts to fill are in small, rural and remote locations, knowing how best to prepare potential principals to survive, at the least, must be of national interest. In the national interest, too, must be the quality of such significant school leaders.

Our paper builds on a decade of research focusing on the principal with the general aim of analysing ways in which principals can work more effectively within the realities of schools as highly complex organisations (for example, Wildy and Dimmock, 1993; Wildy and Louden, 2000). This earlier work identified what principals believe is essential in their professional performance and the contexts across which their practice varies. Recently, we have investigated the role of the novice principal to conceptualise the influences on their work within the contexts of their communities (for example, Clarke and Wildy, 2004). As part of the International Study of Principal Preparation project (ISPP), our research targets principals in their first year in the principalship of small rural and remote primary schools in the West Australian government sector. We have published widely on this topic (Clarke and Stevens, 2004; Clarke, Wildy and Pepper, 2007; Clarke, Stevens and Wildy, 2006; Wildy, 2004; Wildy and Clarke, 2005; Wildy, Clarke and Slater, 2007; Wildy \& Clarke, 2008). Our paper is a synthesis of this body of research and proposes a 
conceptual framework for informing the preparation of principals in the Australian context.

\section{Research approach}

Our approach has been influenced by the view that preparation programs for the principalship are unlikely to be successful if informed mainly from a normative standpoint. Indeed, Murphy and Hallinger (1987) have compared the strategy of seeking to understand the role of the principal with reference to normative theories and models to “ turning on one's high beams to see more clearly in the fog; the area of illumination is increased, yet clarity of vision is reduced" (p. 250). Hence, in accordance with Greenfield's exhortation (1978, p. 137) to engage with the social realities of organisations, our research approach enables us to appreciate what novice principals know and to bring a fresh perspective to the experience of beginning the principalship. We have adopted inductive research methods to inform perspectives on preparation processes which are grounded in principals' practice rather than normative theories or models.

We aimed to portray principals' understandings of the contexts in which they find themselves and their interpretations of the experiences that confront them in their new roles. We seek, also, to ascertain principals' views about their preparedness for the role and what they consider to be their needs for equipping them to perform the role effectively.

Our research approach led us to interview principals in their workplace on a number of occasions during their first year in the position. Using the interview data we constructed short narrative accounts (Wildy, 1999) of problems they encountered and how these were handled as well as their reflections on their experiences. From our research activities conducted over a decade we came to believe that the narrative account offers an effective means of depicting the complexity of principals' work characterised as it is by dealing with dilemmas, interacting with colleagues and the community, and coping with a diversity of professional responsibilities. Our research involved large and small samples, ranging from several hundreds (Wildy and Louden, 2000) to more recent in-depth case studies of between four and six principals (for example, Clarke and Stevens, 2004; Wildy, 2004). We argue that narrative writing generates life-like accounts that can contribute to theory for understanding and theory for improvement (Clarke et al., 2007) because the narrative portrays the abstract so that it is particularised and accessible (Noddings and Witherell, 1991) in contexts that are recognisable to principals.

\section{Findings}

Our work has generated a range of findings. In our earlier research investigating the complexity of novice principals' work in small rural communities we were influenced by themes derived from the literature; for example, accountability, isolation and community (Clarke and Wildy, 2004). Our subsequent work, relating to the theme of 'community', conceptualised principals' experiences according to 'looking in'; 'reaching out'; and 'hanging on' (Clarke et al., 2006). Collectively, these concepts convey the novice principals’ often-tenuous hold on their job.

For this reason, we advocated that their preparation should involve theory and 
practical leadership skill development, as well as rich local contextual knowledge; that they deserve to be well supported by their system colleagues and line managers; and that they need confidence in themselves and to be nurtured by high expectations of success from their system personnel (Wildy, 2004). Throughout our work, we have also recognised the importance of principals' personal resilience (for example, in Clarke et al., 2007).

Our argument that preparation needs of principals in Western Australia require some re-appraisal was reinforced by our comparison of principals' journeys to the position in England, Scotland, Australia and Mexico (Wildy et al., 2007). This comparison revealed the novelty, variety and serendipity that seemed to characterise the journey of the novice principals in Australia and Mexico and highlighted the extent to which preparation for the role is left largely to chance; a situation, it appears, that is reminiscent of arrangements in many African countries (Bush and Oduro, 2006).

More recently, as our research into the preparation of principals progressed, we identified three conspicuous ways in which first year principals (Clarke et al., 2007) believed they needed to re-evaluate their assumptions about the principalship. First, was their realisation that many situations they deal with comprise complex interactions within a range of constituent groups, bringing to the forefront the impact of the interpersonal dimension of the principal's role. Second, principals encounter dilemmas, tensions and even contradictions in their everyday work, particularly in their dealings with various education jurisdictions. Finally, there was some recognition that dealing with human interactions and associated dilemmas entails considerable 'emotional labour'.

These observations have since been refined into the conceptualisation of four key challenges facing novice principals in exercising their roles. Hence, derived from our research over a decade in two Australian states (Western Australia and Queensland) we propose a framework with four focal points: place; people; system; and self (Wildy and Clarke, 2008). While we conceptualise these as distinct foci, we recognise that they are interdependent in complex ways.

\section{A conceptual framework for principal preparation}

The first focus of the framework for principal preparation is Place, which we have come to understand through our research has the deepest impact on novice principals.

Having knowledge and understanding of place means school leaders are able to read the complexities of their context. Sensitivity to context is exceptionally important for leaders located in small, isolated, rural or remote settings. These communities tend to be imbued with particular societal and cultural values, some of which may appear unusual from the urban perspective that many principals will have acquired before appointment.

Having the knowledge, understanding and skill to deal with people means that school leaders are able to handle a range of complex interactions on a day-to-day basis with diverse constituent groups, such as staff, parents, Department personnel, and community members. These interactions highlight the importance of the interpersonal dimension, and the political dimension, of the principal's role. In addition, they need to assess the strategies of others as well as their values and purposes (Blasé, 1991). 
Indeed, the heavily people-centred nature of principals' work occupies a large amount of their daily time and creates an assortment of dilemmas, especially in processes of decision-making. Compounding the challenge of dealing with people in small rural communities is the likelihood that teachers who are colleagues are also parents and members of the school community for whom the school provides a pivotal social function and whose goodwill is critical for the success of novice principals' school improvement efforts.

Having the knowledge, understanding and skill to deal with the education authority, or system in our Australian setting means that school leaders are able to find their way through complex and often baffling bureaucratic regulations, policies and protocols. Working skilfully within the system engenders judgement about what matters, distinguishing among myriad paper and electronic correspondences, what needs immediate attention and what can be left. Dealing with the system, therefore, takes not only knowledge, understanding and skill but also confidence, determination and political sophistication.

Looking after the self means having the personal resilience for the job. Often, novice principals face the challenge of their new appointment at a cost to their confidence, self-efficacy, and ability to manage multiple and competing pressures. Dealing with interpersonal interactions as well as dilemmas and tensions entails unanticipated levels of emotional labour. Self-knowledge and the ability to contextualise, understand, accept and deal with the emotional demands of the job (O'Brien et al., 2003) is a key focus of our framework for principal preparation.

\section{Illustrations}

By way of illustration of both the distinctiveness and the interrelatedness of the four foci of our framework for principal preparation, we present four narratives. The first of the four narratives, entitled Mail plane, shows the importance of the first of the four focal points of the framework: place.

\section{Mail plane}

Four times a week the plane comes in from the nearest regional centre, $1200 \mathrm{~km}$ away. The trip overland would take two days on dirt roads. There are Aboriginal communities between ours and the regional centre, and we are by no means the most remote community. However, the arrival of the plane is an important part of our lives.

I go out to meet the plane. Often I am meeting a visitor to the school who will stay with me in my house. I collect the mail from the plane and I deliver mail and various items for distribution to other communities, the regional centre or further afield.

I could send any other staff member out to the plane. However, meeting the plane has more than practical value. I am there to be seen as an active and public part of the community. So I have a word with a young student who has left school. She is a clever girl, who might bring credit to her community and be a strong role model for her peers. I am encouraging her to go away for further training. I call out to her, 'What you doing, Ellie? You going to [closest regional 
centre]? You coming back to us soon?' I fear, though, that Ellie is not going anywhere.

I catch up with people from the roadhouse, the clinic, and the community office. These are all the people who work in the community. None of the people who work here are Aboriginal people, except our two support staff who liaise between the school and the community. At the mail plane, we don't have time for long conversations. The turn-around time is brief. Besides, the sun is hot and the wind is picking up the dust as the four-wheel drive vehicles roar in. But just seeing each other and having a laugh together helps keep our connections and makes it easy for us to talk when we have serious issues to deal with.

The key issues for principal preparation from this narrative relate to the geographical and social isolation of the place. The particular characteristics of this cultural context - for example, its Aboriginal languages, expectations about work, life expectancy for children, social dysfunction among adults, levels of violence and abuse - are rendered even more challenging by its physical context - extremes of temperature, the absence of rain, little natural vegetation and difficulty of access. Novice principals appointed to such a context would rarely have experienced such a place.

The primary aspect of place that we considered worthy of study in principal preparation programs is understanding the culture of the community in which the school is located. This understanding includes knowledge of local traditions, history, the geography of the area and its productivity, connections with wider communities, as well as local politics and social orders.

However, the narrative Mail plane illustrates more than the challenge of the cultural and physical contexts. We are shown one strategy a principal uses to develop relationships within the community and in doing so promotes her visibility and her credibility as a community leader. Relationships, visibility and credibility are key aspects of place that are prerequisites, we believe, for initiating school improvement because of the conservative nature of many rural and remote communities, especially in relation to educational change (Clarke, 2002b). Moreover, our studies have shown that supporting teachers in their classroom management or fine-tuning their teaching strategies for the needs of their students, takes perseverance and deep understanding of the complexities of initiating, implementing and sustaining change. However, novice principals do not always have these skills and understandings (Wildy, 2004), which take time to develop. Leaving such development to chance, to occur on-the-job, without preparation, is a risky business (Wildy et al., 2007).

While Mail plane was chosen to illustrate the importance of place, this narrative also illustrates the connection between place and people in the building of relationships with the community members; and between place and self in the development of the principal's credibility. Ironically, this narrative provides counter-intuitive illustration of the use of a principal's time. From a management perspective, it might be argued that the principal's time would be more wisely spent at the school, with her teachers and her students. The registrar might have met the mail plane just as effectively. However, from a leadership perspective, the principal is using her time productively because without strong community relationships, in this context, her school-level initiatives would be undermined. Although we do not eschew the inclusion of 
developing technical skills in the preparation of principals, we maintain that the most meaningful programs will concentrate on leadership, rather than on management or administration. Therefore, instead of concentrating on technically oriented notions of administration, programs should create opportunities for prospective principals to develop insights into the nature of school leadership by focusing on the meaning of human action (Greenfield, 1978) as determined by the realities of complex organisations in context.

The second of the four narratives, entitled I love the days I teach, shows the importance of the second of the focal points of the framework: people.

\section{I love the days I teach}

When I am in the classroom as the Science teacher I think: 'I feel good to be here. I know how to do this.' After 20 years teaching, I am at ease working with students. On the days I teach I regain my sense of self and my confidence. In contrast, when I am in the principal's office I am hesitant. I wonder if this is how the job is done. I am less at ease working with staff. I have much to learn and wonder how long it will take me to gain a sense of professional expertise as a manager and a leader in the school.

Managing parents is not always straightforward. For example, I had an altercation with a parent from a neighbouring school last term. We hosted the interschool athletics, competing against two neighbouring schools. Together with our teachers, I planned the program of events. But two days before the carnival I had a phone call from the president of one of the school's parents' association. She was unhappy about the order of races: How dare we put the $400 \mathrm{~m}$ event early in the program instead of at the end of the program as a fitting climax for the day. I was stunned by her angry 30 minutes on the phone. I told her I would consult the other principals and ring her back the next day. The principals reassured me it was immaterial to them and her school's principal sent out an email reminding them about the carnival and telling them of the order of events. I phoned her next morning and explained that we would not be changing the order of events and that I looked forward to welcoming her to our school for the carnival. I was disappointed when she did not come to say hello, although I knew she was at the carnival.

My greatest challenge is working with my teachers. One teacher causes me ongoing discomfort. Our junior teacher wants her assistant to have the same preparation time as she has, and at the same time. I had heard from my predecessor that this was what the junior teacher required and that, to keep the peace, she had agreed. When I arrived at the school I did my homework and established that assistants did not have preparation time. I checked with the District Office, the principals' association and with principals in my local network. So when the junior teacher approached me on the matter I stood firm. This teacher is a parent of students at the school. She is also related to the other full time teacher, and to many people in the community. I could not afford to fall out with her. Next time she came to me, I adjusted her timetable so that there was some time when she and her assistant were free together. I thought we had resolved the matter. However, a week later she came to me, complaining 
that she could not do her job without common preparation time with her assistant. I continued to stand firm. I gave her responsibility for resolving the matter by suggesting she talk to other junior teachers in our network. However, at the start of the next term she was back to me with the same complaint. In her mind the matter was not resolved.

The key issues for principal preparation from this narrative relate to meeting the needs of teachers and parents without contravening policies or compromising traditional practices. Handling conflict is not easy, especially when the principal's confidence is low. However, the issues for this novice principal are more complex because teachers in small communities are frequently parents in the school community, and they can wield considerable social pressure among their peers. Further, as members of the community, teachers can have long histories, and might well have witnessed numerous novice principals struggling to learn the job. The challenge of dealing with people is compounded by the conservative nature of small rural and remote communities, especially when the principal is perceived to be young, inexperienced and unfamiliar with the unspoken rules, culture and expectations of the community.

The primary aspect of people that we consider worthy of study in principal preparation programs is the set of interpersonal skills to work constructively with adults from a diversity of backgrounds. Building relationships with members of the school community, enhancing teachers' capacity, handling conflict between adults, coping with the demands of parents and teachers, and working with poorly performing teachers to improve performance are aspects of dealing with people that it would be desirable to include in a principal preparation program.

While I love the days I teach was chosen to illustrate the key concept of people in our conceptual framework, this narrative also illustrates other concepts that are interrelated to people. Place is again important here: the role of culture is shown by the parent's determination to have the order of events maintained because definite ways of doing things had been firmly established. Self is also important: principals in small schools do many jobs, such as organising sports carnivals, that in larger schools might be delegated. Further, it might be argued that a confident leader might want to relent on some points to conserve energy for larger, more important issues. Here, as in the previous narrative, learning how to balance the management and leadership aspects of the job is critical for principal preparation.

The third of the four narratives, entitled You're on your own shows the importance of the third of the focal points of the framework: system.

You're on your own

This is a small school, which should make it easier for me to keep on top of things. However, I never know whether I'm doing the right things, day-to-day and week-by-week.

You're on your own. The school is 60 kilometres from the nearest town so the physical isolation could get you down. What I feel more keenly though is the professional isolation. The District Director only comes down when it's time to 
review the school. I don't even have a Deputy to give me advice. In fact, I rely heavily on my Registrar, a local resident who has been here for 10 years.

I don't seem to get direction from anyone. Everything seemed to be going all right. I started to relax and even enjoy the job and then out of the blue I received a memo from the District Director asking "What are you going to do about the [new reporting policy]?” I had to admit that I had not heard of this policy. It must have come through an email I missed. Perhaps it was discussed at a principals' meeting I couldn't attend because our relief teacher was not available. After that experience I started to worry whether I was attending to all aspects of the job.

I need a good mentor, someone who will respond to my calls, when I need help and who will give me the kind of help to act quickly.

The key issues for principal preparation from this narrative relate to the principal's relationship with the education authority. In the Australian context, the government education authority is highly centralised in each state, with a central office in the capital city, and regional offices spread across the jurisdiction. In a sparsely populated state like Western Australia, with 0.5 million of its 2 million population located mainly around the coast of an area one third the size of China, the regional offices are widely dispersed and each one services up to 50 schools. It is not surprising that principals like this one feel professionally alone. Keeping abreast of policy shifts in a distant bureaucracy may not figure prominently in the consciousness of a novice principal situated in a remote part of the state.

The primary aspect of system that we consider worthy of study in principal preparation programs is understanding the nature and role of the system in relation to the principalship. Such understanding implies knowing system policies, processes and protocols; networking among system personnel; balancing system imperatives with local needs; and developing the skills and knowledge to acquire the resources needed in a small and isolated school.

The narrative You're on your own demonstrates more than the challenge of keeping connected to the system. Place is clearly important and so too is building relationships with significant people in the community such as the Registrar who is the keeper of the school and community culture. Equally important is the effect of isolation on this principal's self, when messages from the District Director serve not to support but to undermine the principal's confidence. The principal has yet to develop the skill to seek the support required and the knowledge to locate the source of such support.

The last of the four narratives, entitled Not distracted, shows the importance of the fourth focal point of the framework: self.

\section{Not Distracted}

At the end of my workday I drive the short distance to my home. The dog greets me warmly and I spend time relaxing, reading the paper and mail. Coming home is a welcome respite from school. I live alone so I can please myself about what and when I eat. Usually I make a toasted sandwich and watch TV. Then I 
do some schoolwork. There's no time for commitments outside of teaching. I have been invited to join book clubs and other social groups but I can't afford the time. I don't play any sports and I don't entertain so I don't have to bother about shopping or cooking. For a treat I occasionally walk down to the restaurant and enjoy a decent meal.

I like my own company and the peace around me. The bush is close to the town. I notice the change of seasons by the sound of the birds and the wildflowers that spring up and cover the red dirt. Small farming communities like this have a cycle of their own - seeding and harvesting, busy and quiet times. The country has its beauty too. In a small country town I don't worry about dressing up. I wear tracksuit pants and trainers because I teach Physical Education each day.

I knew that this would be a long and lonely haul. I was prepared to give all my attention to becoming a successful teaching principal. I have few distractions so I can get on with the job.

The primary aspect of self that we consider worthy of study in principal preparation programs is developing personal resilience. Included in the development of personal resilience is balancing professional work and personal life needs; coping with the high visibility of the position; building confidence as a leader; and coping with professional and physical isolation.

However, the narrative Not distracted demonstrates more than the challenge of personal resilience. The traditions of place together with the social and political linkages of the people compound this principal's discomfort. The narrative also illustrates the absence of support from system personnel to shape the expectations that the principal brings to the job and her difficulty in harnessing the support.

\section{Conclusion}

We argue that collectively our narrative accounts capture the tenor of novice principals' voices and provide a rich portrayal of what they do, need and feel (Walker and Qian, 2006). From this rich portrayal of principals' day-to-day work we have articulated a framework for principals' preparation - place, people, system and self that seems to support Day and colleagues' contention (2001) that the experience of being a leader arises from a complex interplay of personal ideologies, relationships with staff [and significant others], and the demands of the school situation.

We believe, therefore, that our framework has potential to inform principal preparation processes going beyond dealing with routine management and administrative tasks. Perhaps this narrower approach is suitable for informing prospective leaders about the necessary functional knowledge and skills to undertake their every day responsibilities within the system (Dempster, 2001). Nevertheless, we suggest that in order to accommodate the other elements within our framework it is vital to engage leaders with the breadth of experiences and challenges of modern school leadership that can equip them for the complexity of their roles. These processes, however, are unlikely to be effective if they are pursued haphazardly and episodically. Instead, leadership knowledge, dispositions and skills need to be acquired through gradual, iterative and reflective learning. 
This observation is especially pertinent to people and self, areas in which it takes considerable time for school leaders to develop their capacity. If fundamental qualities of these two leadership areas such as communication, collaboration, teamwork and resilience are to be facilitated, the cognitive landscape of principal preparation, at least in Australia, would benefit from some enhancement. At the very least, greater emphasis could be placed on the kind of action learning that engages with real work problems and assists individuals to find solutions. In similar vein, preparation programs could develop school leaders' efficacy in dealing with people and self through activities that promote structured reflection on practice and selfanalysis.

Our focus on place highlights the need for principals to be 'contextually literate' (National College for School Leadership, 2007). The requirement of school leaders to be able to read the complexities of their contexts suggests that principal preparation programs might benefit from incorporating knowledge of the school in a community, how communities work and how principals can work effectively with community partners. It would also be helpful if these considerations could be tailored to fit distinctive contextual circumstances such as those applying to small communities located in rural and remote environments.

Although novice principals will always resort to on-the-job learning, it should not be necessary for them to rely exclusively on trial and error to acquaint themselves with the role. We are not suggesting that our framework will provide a panacea to the vexed matter of preparation for the principalship. We do argue, however, that the framework has potential to be used as a heuristic tool for connecting with principals' day-to-day work and the professional knowledge, skills and dispositions that are required to perform this work effectively. We suggest that, rethinking the processes by which principals are prepared along the lines suggested, will assist these L-plate drivers in the principal's office to use their rear view mirror judiciously to understand how they should be doing their work in the present and the future. In this way, they are more likely to proceed securely and confidently along the frenetic highway of the principalship.

\section{References}

Blasé, J. (1991), The Politics of Life in Schools: Power, Conflict and Cooperation, Sage, Newbury Park.

Bush, T. (2006), "New principals in Africa: preparation, induction and practice", Journal of Educational Administration, Vol. 44 No. 4, pp. 359-375.

Clarke, S.R.P. (2003), Mastering the art of extreme juggling. An examination of the contemporary role of the Queensland teaching principal, Report prepared for the Queensland Association of State School Principals.

Clarke, S. (2002a), "The teaching principal: From the shadowlands to a place in the sun”, The Queensland Journal of Educational Research, Vol. 18 No.1, pp. 23-37. 
Clarke, S. (2002b), "Understanding small school leadership: Listening to the practitioners”, The Practising Administrator, Vol. 24 No. 3, pp. 28-32.

Clarke, S. and Wildy, H. (2004), "Context counts: Viewing small school leadership from the inside out”, Journal of Educational Administration, Vol. 42 No. 5, pp. 555572.

Clarke, S. and Stevens, E. (2004), Small schools leadership study. Leading and teaching in small schools: Confronting contextual complexity in work practices, Report prepared for Education Queensland.

Clarke, S., Stevens, E. and Wildy, H. (2006), "Rural rides in Queensland: Travels with novice teaching principals", International Journal of Leadership in Education, Vol. 9 No. 1, pp.75-88.

Clarke, S., Wildy, H. and Pepper, C. (2007), “Connecting preparation with reality: Primary principals' experiences of their first year out in Western Australia”, Leading \& Managing, Vol. 13 No. 1, pp. 81-90.

d'Arbon, T., Duignan P. and Duncan, D. (2002), "Planning for future leadership of schools: An Australian study”, Journal of Educational Administration, Vol. 40 No. 5, 468-485.

Day, C., Harris, A. and Hadfield, M. (2001), "Grounding knowledge of schools in stakeholder realities: A multiperspective study of effective school leaders”, School Leadership \& Management, Vol. 21 No. 1, pp. 19-42.

Dempster, N. (2001), The professional development of school principals: a fine balance, Professorial lecture, Griffith Public Lecture Series, 24 May, Griffith University, Brisbane.

Dunning, G. (1993), "Managing the small primary school: The problem role of the teaching head”, Educational Management Administration and Leadership, Vol. 21 No. 2, pp. 79-89.

Eraut, M. (1994), Developing Professional Knowledge and Competence, The Falmer Press, London.

Greenfield, T. B. (1978), "The decline and fall of science in educational administration”, in Westoby, A. (1988) (Ed), Culture and Power in Educational Organisations, Open University Press, Milton Keynes, pp. 115-141.

Mohr, N. (2000), "Small schools are not large schools: Potential pitfalls and implications for leadership”, in Ayers, W., Klonsky, M. and Lyon, G. (Eds.), A simple justice: The challenge of small schools, Teachers College Press, New York.

Murphy, J. and Hallinger, P. (1987), "New directions in the professional development of school administrators: A synthesis and suggestions for improvement”, in Murphy, J. and Hallinger, P. (Eds.), Approaches to Administrative Training in Education, State University of New York Press, Albany, pp. 245-273. 
National College for School Leadership (2007), "What we know about school leadership”, available at: www.ncsl.org.uk/publications (accessed 25 January 2008).

Noddings, N. and Witherell, C. (1991), "Epilogue. Themes remembered and foreseen", in Witherell, C. and Noddings, N. (Eds.), Stories lives tell. Narrative and dialogue in Education, Teachers College Press, New York, pp. 279-280.

Nolan, B. (1998), "Implementing departmental policy changes in one-teacher schools”, Journal of Educational Administration, Vol. 36 No. 3-4, pp. 262-285.

O’Brien J., Murphy D. and Draper J. (2003), School Leadership. Policy and Practice in Education (Number 9), Dunedin Academic Press, Edinburgh.

Preston, B. (2005), Teacher supply and demand to 2005: Projections and issue, A report commissioned by the Australian Council of Deans of Education, Canberra, available at: http://acde.edu.au/publications.htm.

Sackney, L. and Walker, K. (2006), "Canadian perspectives on beginning principals: their role in building capacity for learning communities”, Journal of Educational Administration, Vol. 44, No. 4, pp. 341- 358.

Southworth, G. (1999), A Teacher Training Agency report into successful heads of small primary schools, School of Education, University of Reading.

Su, Z., Gamage, D. and Mininberg, E. (2003), "Professional preparation and development of school leaders in Australia and the USA", International Education Journal, Vol. 4 No.1, pp. 42-59.

Rutter, M., Maughan, B., Mortimore, P., Ouston, J. and Smith, A. (1979), Fifteen thousand hours: Secondary schools and their effects, Open Books, London.

Walker, A. and Qian, H. (2006), "Beginning principals: balancing at the top of the greasy pole”, Journal of Educational Administration, Vol. 44, No 4, pp. 297-309.

Webb, R. and Vulliamy, G. (1995), "The changing role of the primary-school headteacher”, Educational Management Administration and Leadership, Vol. 24 No. 3, pp. 301-315.

Wildy, H. (1999), "Statues, lenses and crystals: Looking at qualitative research", Educational Research and Perspectives, Vol. 26 No. 2, pp. 61-72.

Wildy, H. (2004), Small schools leadership study Leading and teaching in small schools: Confronting contextual complexity in work practices, Report prepared for the Western Australian Department of Education and Training, available at: http://www.eddept.wa.edu.au/cpr/publications.htm.

Wildy, H. and Clarke, S. (2008), "Charting an arid landscape: The preparation of novice primary principals in Western Australia”, School Leadership and Management. Vol 28 No 5, pp.469-487. 
Wildy, H. and Clarke, S. R. P. (2005), "Leading the small rural school: The case of the novice principal”, Leading \& Managing, Vol. 11 No. 1, pp. 43-56.

Wildy, H., Clarke, S. and Slater, C. (2007), "International perspectives of principal preparation: How does Australia fare?”, Leading \& Managing Special Edition, Vol. 13 No. 2, pp. 1-14.

Wildy, H. and Dimmock, C. (1993), "Instructional leadership in Western Australian primary and secondary schools”, Journal of Educational Administration, Vol. 31 No.2, pp. 43-62.

Wildy, H. and Louden, W. (2000), "School restructuring and the dilemmas of principals’ work”, Educational Management and Administration, Vol. 28 No. 3, pp. 173-184.

Wilson, V. (2007), Leadership in small Scottish primary schools, Report prepared for the Education Information and Analytical Services Division of the Scottish Government. 